\title{
EDITORIAL
}

\section{A propósito de los proyectos de reforma a la salud}

\author{
Julio César CAstellanos Ramírez ${ }^{1}$
}

En los días de trámite y gestión de las leyes Estatutaria y Ordinaria de Salud, muchas organizaciones asumen la vocería y compromiso de defender el derecho fundamental a la vida y el acceso a salud e, incluso, excepto muy pocas posturas que se fundamentan en el equilibrio económico del sistema, las razones aducidas para una u otra propuesta son el beneficio y bienestar del paciente o usuario del Sistema.

El liderazgo contemporáneo impone la necesidad de transformar la realidad. Y más en Colombia, país en el cual el desempleo, la pobreza y la desigualdad crecen año a año. No es concebible que se mantenga un discurso en defensa del paciente desde la postura del trabajador de salud, el administrador, el poder local, regional o nacional, en el Ejecutivo o en el Legislativo y el líder se dedique a recibir las prebendas de los gajes del poder o la voz y a mantener el status quo protegiendo solo los intereses particulares de la organización que representa o en ocasiones favoreciendo los de terceros con intereses meramente económicos.

Es impensable pensar y exigir que una norma general sea aceptada y compartida en su totalidad por cualquiera de los actores sociales o grupos de presión involucrados o afectados por ella, por lo cual estos comentarios buscan apartarse de lo que como hospital universitario nos puede afectar y se generan en un análisis de los

1 Médico cirujano. Especialista en Gerencia Hospitalaria y Salud Ocupacional. Magíster en Estudios Políticos. Director general del Hospital Universitario San Ignacio y docente de cátedra de la Facultad de Ciencias Económicas de la Pontificia Universidad Javeriana. Docente Ad Honorem de la Facultad de Medicina de la Pontificia Universidad Javeriana. 
que puede hacer más o menos difícil el acceso a los servicios de salud de los pacientes y la atención a los usuarios (pacientes y acompañantes).

Por tanto, para estos comentarios se tomarán como fundamentos de análisis dos premisas:

La salud como derecho humano. La salud es un derecho humano que trasciende su manejo como un bien asegurable. El preámbulo de la Declaración Universal de los Derechos Humanos establece: "Considerando que la libertad, la justicia y la paz en el mundo tienen por base el reconocimiento de la dignidad intrínseca y de los derechos iguales e inalienables de todos los miembros de la familia humana", dejando la base en que la orientación de su formulación es la dignidad humana sin más consideraciones y hace referencia a la salud y su asistencia en el artículo 25 , el cual textualmente declara: "Toda persona tiene derecho a un nivel de vida adecuado que le asegure, así como a su familia, la salud y el bienestar, y en especial la alimentación, el vestido, la vivienda, la asistencia médica y los servicios sociales necesarios; tiene asimismo derecho a los seguros en caso de desempleo, enfermedad, invalidez, viudez, vejez y otros casos de pérdida de sus medios de subsistencia por circunstancias independientes de su voluntad" (cursivas fuera de texto). Así, el seguro es una cobertura adicional económica para el tiempo de enfermedad; mientras que el derecho a la salud y la asistencia médica son independientes, en cuanto la salud es el resultado de ese nivel de vida adecuado que asume la declaración como derecho, precisando que la asistencia médica es uno de los componentes especiales del nivel de vida adecuado.

La salud como asunto económico. Es necesario entender que la economía y la salud están íntimamente relacionadas, por cuanto un país con una economía sana y gran equidad tendrá condiciones más favorables para un nivel de vida adecuado. Para la política pública se necesita un acertado manejo de lo económico en especial de la hacienda pública, por lo cual el enfoque económico en una reforma estructural de salud debe corresponder a la aplicación de la economía del bienestar, que se define en el diccionario de la Real Academia Española como: economía que tiene como objetivo global extender a todos los sectores sociales los servicios y medios fundamentales para una vida digna. Y este caso el servicio central es la salud, alejándose del concepto y costumbre que en nuestro país se ha consolidado en los últimos años de tratarla como un sector de la producción de servicios y consumo para la extracción de renta y con el objetivo central de producir riqueza en términos monetarios. 
En estos años de crisis de la salud, sentida, reconocida y padecida por la sociedad colombiana en todos sus grupos, regiones y estratos socioeconómicos, cursan por primera vez en muchos años dos proyectos de ley: uno estatutario, que busca reglamentar el acceso al derecho fundamental, y uno ordinario, que busca transformar el estado actual de la situación y mejorar las condiciones de garantía en el acceso a la salud de los colombianos y colombianas.

Con base en lo anterior, consideramos que el Proyecto de Ley 209 de 2013 Senado, 267 de 2013 Cámara, por medio de la cual se regula el derecho fundamental a la salud y se dictan otras disposiciones, es un documento sencillo de leer en algunas páginas y veintiún artículos que cumple en sus objetivos y postulados con las bases de análisis aquí planteadas y las consideraciones que ha hecho la Corte Constitucional sobre la materia. Sin embargo, su aprobación no resuelve de forma y en lo cotidiano las dificultades que los usuarios del sistema atraviesan y la crisis de la salud.

Este texto se centra principalmente sobre el Proyecto de Ley 210 de 2013 Senado "por medio de la cual se redefine el sistema general de seguridad social en salud y se dictan otras disposiciones" y sus acumulados 233 de 2013 y 051 de 2012 Senado, un texto más complejo de revisar en 27 páginas, que contiene 90 artículos, que cumple en sus objetivos, postulados y artículos iniciales con la necesidad que tiene el país de hacer una reforma centrada en el usuario y propendiendo por un mejor uso de los recursos del sector en beneficio de los pacientes, lo cual se puede ver hasta el artículo 17 del proyecto.

Aunque el proyecto tiene coherencia y unidad de materia con lo expuesto hasta el artículo 43 y los capítulos IX y X, aparecen varios puntos que definitivamente preocupan, en cuanto van contra los principios y fundamentos expuestos en este análisis y los primeros artículos del proyecto, los cuales se presentarán a continuación, para comentar posteriormente sobre los capítulos VII y VIII y terminar con algunos comentarios adicionales de forma.

\section{Comentarios a los capítulos I-VII y IX-X}

1. Se ratifica ninguna integración vertical, lo que favorece y promueve la mejor atención de los pacientes sin que medien intereses económicos directos de favorecimiento de instituciones por intereses distintos a los resultados y desenlaces clínicos.

2. Empieza insinuarse que el cambio no es tan sustancial como se desprende la intención de los capítulos iniciales, cuando en el artículo 20 se anota: "La gestión 
y autorización de pago de los servicios y tecnologías de salud de Mi-Plan estará a cargo de los Gestores de Servicios de Salud, los cuales no podrán realizar recobros por ningún tipo de atención", una entidad solo recobra cuando hace pagos, entonces ¿cómo es posible hacer recobros si no pagarán dineros?

3. En el parágrafo 2 del mismo artículo 20 se habla de una manual emitido por el Ministerio: ¿al fin quién administra: Salud-Mía o el Ministerio?, y dicho manual ¿sobre qué base se elaborará, y al desaparecer el Fosyga qué pasará con el único manual ajustado al cambio económico del país y demás, el manual SOAT?

4. Artículo 27. Las redes de salud deben ser una respuesta a problemas públicos de salud y al dejar su conformación en manos de los gestores de nuevo generan un riesgo de selección por criterio de tarifa, sin calidad, como pasa actualmente, más aún cuando los gestores son corresponsables financieros. El riesgo será menor en regiones de un solo gestor, pero incrementará en las áreas sanitarias mayores donde operen varios simultáneamente. Definitivamente este es un asunto de reglamentación y dirección pública con participación de IPS públicas y privadas.

5. Si los gestores solo operan una red, para qué un gestor. Como está en el artículo 31, no se justifica el gestor, la red se opera a sí misma, el gestor tiene la obligación de supervisar la calidad de servicio en Mi-Plan de la Red y gestionar las relaciones administrativas entre la Red y Salud-Mía.

6. Si las entidades de gestión serán sociedades comerciales, todo el manejo administrativo deberá regirse por el Código de Comercio y este proyecto propone cambios y limitaciones en la vigencia de cuentas y facturas que lo alejan del Código de Comercio, rompen la unidad de materia y consideramos no se justifican de modo alguno.

7. Si los gestores en salud prestan servicios de planes complementarios, como se anota en el literal $b$ del artículo 32, se alejan de su objetivo central y empiezan a jugar como pagadores y contratantes directos sobre su propios recursos; además, entraría a la limitación de integración vertical y se favorecía el cruce entre lo POS y lo complementario.

8. El literal $i$ del artículo 32 da la idea que Salud-Mía va a comprar medicamentos y dispositivos médicos directamente, lo cual puede ser una buena estrategia para mejorar costos y sostenibilidad del sistema, pero tiene el mismo riesgo que actualmente se tiene con las "malas" EPS, que se trate de imponer un insumo que no sea aceptado por los prestadores en razón a criterios de calidad. 
9. Una gran contradicción entre lo anotado en los principios de la Ley y lo que al final funcionará se encuentra en el literal $p$ del mencionado artículo 32 cuando textualmente se anota: "Garantizar las prestaciones individuales de Mi-Plan, con cargo al valor de los recursos que reciba para el efecto y a su patrimonio, en caso de no ser suficiente. Con el propósito de soportar las necesidades de financiamiento en la prestación de servicios deberán contar y mantener una reserva en Salud-Mía para respaldar obligaciones con los Prestadores de Servicios de Salud'. Esto son las mismas EPS de hoy. ¿Al fin qué? Si las obligaciones son de Salud-Mía con los prestadores, auditadas por los gestores, ¿por qué se incluye este inciso? Esto se ratifica cuando el artículo 39 anota que los gestores tendrán un pago per cápita ajustado por riesgo para cubrir el costo de las prestaciones individuales de Mi-Plan, lo cual insinúa que sí van a pagar directamente con cargo a recursos asignados (lo mismo de ahora). De pronto estamos equivocados y es una redacción que algunos no tenemos capacidad de entender, pero creemos que es necesario aclararla muy bien.

10. En el artículo 36 se evidencia que se espera seguir con la inequidad del régimen subsidiado y contributivo. Como lo ha ordenado la Corte Constitucional de Colombia, excluyendo los regímenes de excepción, requiere un Sistema con un Único Plan de Beneficios, que se financia con recursos públicos y privados. Este artículo, como está redactado, da pie para facilitar en el futuro inequidades, lo cual vuelve a aparecer en el parágrafo dos del artículo 87: "El Ministerio de Salud y Protección Social podrá disponer de los recursos del Sistema General de Participaciones de oferta pública para financiar el valor por persona de MiPlan y definir la transformación de recursos de oferta pública a Régimen Subsidiado".

11. Los capítulos finales los consideramos adecuados y mejoran las medidas de control y sanción y la transmisión está planteada de manera responsable, pero quedan algunas inquietudes que deben tenerse en cuenta:

a. El literal $b$ del artículo 87 establece la financiación de la denominada población pobre no asegurada para la oferta mínima esencial en condiciones de eficiencia, sin definir los alcances de "oferta mínima esencial".

b. El parágrafo del mismo artículo limita a las reformas legales el incremento de año a año de los aportes patronales. No es claro la intención de este artículo, en cuanto en general es esa la única manera de modificarlas; por otra parte ¿esto quiere decir que si un empleador sube el salario por en- 
cima del salario mínimo o la inflación (condición legal), los aportes solo aumentarán hasta el IPC?

Finalmente, el artículo 90 de vigencias y derogatorias confirma que seguiremos en la selva de los laberintos legales, derogaciones parciales de leyes anteriores que en ausencia de reglamentación de las más nuevas continuarán vigentes y hacen que sea muy complejo definir al final qué está vigente y qué no. Esperemos que se ilumine al legislador y en la nueva ley incorpore lo que debe quedar vigente y derogue la totalidad de lo anterior; esto facilita el seguimiento y gestión del sistema y, en últimas, facilita la vida y el acceso a los usuarios.

\section{Comentarios al capítulo VII}

1. Sin unidad de materia con el resto de la Ley. El capítulo VII habla del talento humano en salud; pero reglamenta de manera parcial y descoordinada con el Ministerio de Educación la formación de posgrado en Medicina. Por tanto, es un título rimbombante que desdeña las demás profesiones técnicas, tecnológicas y universitarias involucradas en el cuidado de la salud.

2. Al no tener un modelo de atención en salud definido, en especial con las facultades y competencias asistenciales de los profesionales de enfermería y medicina y luego de las especialidades en razón a la población y los problemas de salud y enfermedad, la reglamentación parcial de un aspecto solo generará más problemas.

3. En el artículo 45, sobre cupos de residentes, sería más interesante una figura de REGULACIÓN con definiciones de oferta y demanda acorde a las regiones y por población, más que la oferta ilimitada en el crecimiento del número, por ejemplo, el aumento en el número de facultades de medicina no mejoró la calidad; además, solo el $33 \%$ están acreditadas.

4. El pago de residentes a partir del 2016 debe estar financiado de manera diferente, por cuanto al final los pagos se harán con cargo a las tarifas y costos del Sistema General de Seguridad Social. Se debe es aportar un presupuesto del Ministerio a Salud-Mía para cubrir una diferencia tarifaria entre los hospitales universitarios reconocidos y los demás; el pago por transferencia de presupuesto, en los hospitales públicos, dejando los "préstamos beca" para los residentes que rotan o toman su posgrado en una institución privada, es inequitativo. Ya es hora de que el Gobierno asuma el tema de la educación de posgrado en salud como una 
política pública que puede estar operada por públicos y privados, pero sobre la base del interés público y unas reglas del juego equitativas y serias. Esta falta de consistencia se confirma cuando en el artículo 47 se anota: "los residentes de Instituciones Prestadoras de Servicios de Salud privadas no cuenten con vínculo laboral, puedan participar como beneficiarios del programa".

\section{Comentarios al capítulo VIII}

Propone un cambio en el funcionamiento de las empresas sociales del Estado (ESE) que no tiene unidad de materia con el tema de Seguridad Social en Salud, modifica muchas condiciones y se involucra con otras leyes y estatutos (como carrera administrativa, servicio social, código laboral), vuelve a crear una nueva categoría de trabajador en salud (ya fracasado en ocasiones anteriores) y busca en esa nueva categoría una menor estabilidad del empleo, lo que en razón a ser este derecho fundamental solo podría ser abordado por una ley estatutaria.

Prohíbe la exclusividad, como si esta no se pudiera pactar libremente entre empleador y empleado, olvidando que un criterio de calidad es contar con profesionales de tiempo completo y dedicación exclusiva que aporten mayor pertenencia y mejoren la asistencia a los usuarios.

Este capítulo requiere un debate a fondo entre los directivos y trabajadores de las ESE, por cuanto nada de lo aquí anotado aporta a mejorar la calidad del servicio a los pacientes y al funcionamiento del Sistema General de Seguridad Social. Si bien algunos de los puntos pueden aportar a mejorar la gobernabilidad y sostenibilidad de estas entidades, definitivamente es parte de otro tema y debate.

\section{Comentarios de estructura y forma}

1. El artículo 18. La junta directiva, como está creada y reglamentada, es poco participativa, presenta gran inestabilidad y está sujeta a los vaivenes emocionales o clientelistas del presidente de turno. Proponemos dos opciones: a) una junta con estructura, funciones y nombramiento similar a la del Banco de la República con mínimo siete miembros, y b) reactivar el Consejo Nacional de Seguridad Social, con reuniones trimestrales o semestrales para formulación de política macro del sistema, en cuyo seno se nombre la junta directiva que sesionará mensualmente. 
2. En el capítulo VII: los artículos 49 y 50 tocan de manera tímida y superficial otros aspectos que siendo importantes aparecen como insertos sin mayor trascendencia en este texto.

3. En el artículo 26 falta delimitar mejor la relación funcional esperada para el tema de urgencias entre los prestadores primarios y los complementarios.

4. Creemos se crea una zona gris con el artículo 43: “Ajuste y redistribución de riesgo. El Ministerio de Salud y Protección Social determinará los mecanismos de redistribución y compensación de riesgo entre los gestores de servicios de salud tomando en cuenta criterios etarios, poblacionales, geográficos, epidemiológicos o de alto costo por frecuencia de eventos o patologías". Esto debe quedar más claro especialmente para quienes estén estudiando la posibilidad de ser gestores.

Finalmente, es posible que al salir este texto impreso ya se conozcan los desenlaces de estos procesos, en especial el del proyecto de ley estatutaria; por lo cual, independiente del fondo y forma que den las leyes, los invito a que transformemos la realidad y defendamos los derechos del paciente en lo cotidiano con nuestra amabilidad, dándole la mayor seguridad clínica, informándolo sobre sus deberes y derechos, ayudándolo a superar las barreras del sistema, con un buen diagnóstico, bridando atención oportuna, haciendo uso racional de los recursos, cuidando con celo los recursos económicos del sistema para el beneficio de los pacientes, e incluso asumiendo la vocería que nos sea posible para defenderlos en los espacios públicos de debate. En fin, nuestra defensa de la salud y los derechos del paciente nos exige: SER PARTE DE LA SOLUCIÓN Y DEJAR DE SER PARTE DEL PROBLEMA. 